\title{
Corrupção urbanística em sistemas de planejamento e gestão urbanos: um estudo de caso
}

Land-use corruption in urban management and planning systems: a case study

Leonardo Beraldo de Ornellas Borges[a] (D), Jonathas Magalhães Pereira da Silva[a]

[a] Pontifícia Universidade Católica de Campinas (PUC-Campinas), Programa de Pós-graduação em Urbanismo (PosUrb), Campinas, SP, Brasil

Como citar: Borges, L. B. O., \& Silva, J. M. P. (2019). Corrupção urbanística em sistemas de planejamento e gestão urbanos: um estudo de caso. urbe. Revista Brasileira de Gestão Urbana, 11, e20180056. https://doi.org/10.1590/21753369.011.002.A006

\section{Resumo}

0 presente trabalho problematiza as dificuldades encontradas na gestão urbana relacionadas à corrupção urbanística, isto é, ações com protagonismo de agentes públicos e privados que se utilizam do sistema de planejamento para o benefício próprio ou de um determinado grupo. Investigam-se mecanismos que, inseridos nos sistemas de planejamento, podem potencializar transações corruptas, por meio de uma revisão da literatura que trata da corrupção urbanística, busca delinear quais elementos contribuiriam para esta dinâmica. Para isso, o trabalho foi estruturado a partir de um estudo de caso, que analisou a dinâmica de um sistema de planejamento e gestão em um município paulista durante o intervalo de 1985-2016. Os dados levantados, de metodologia analítica qualitativo, baseada em documentos oficiais como: processos jurídicos, legislação urbanística, assim como notícias veiculadas no período, possibilitam a identificação dos atores participantes nos processos de expansão urbana no período. 0 estudo de caso dialoga com elementos encontrados na literatura que permitem a construção de um método de trabalho que estabelece suas categorias de analises formadas por fatores indutores da corrupção urbanística como: a alta discricionariedade, a opacidade procedimental e o direcionamento normativo. Assim, este estudo apresenta de que forma determinados mecanismos auxiliaram na obtenção de privilégios nestes processos.

Palavras-chave: Corrupção urbanística. Planejamento urbano. Gestão urbana. Cidades médias. Políticas urbanas.

\section{Abstract}

This paper seeks to assist in the understanding of the difficulties found in urban management related to urban corruption, defined by actions with protagonist of public and private agents who use the planning system for their own benefit or for a particular group. Some mechanisms are investigated that, inserted in the planning systems, can potentiate corrupt transactions. Through a literature review dealing with urban corruption, it seeks to outline which elements would contribute to this dynamic. The work was structured 
through a case study, which analyzed the dynamics of a planning and management system in a city of São Paulo during the period 1985-2016. The data collected, using a qualitative analytical method, based on official documents such as: legal processes, urban legislation and newspapers in the period, which allow the identification of the actors involved in the processes of urban expansion in the period. The case study dialogues with elements found in the literature allowing the construction of a work method that establishes its categories of analysis formed by factors inducing urban corruption such as: high discretion, procedural opacity and normative direction. The paper presents how certain mechanisms helped to obtain privileges in these processes.

Keywords: Land-use corruption. Urban planning. Urban management. Medium cities. Urban policies.

\section{Introdução: corrupção e urbanismo}

No Brasil, o tema corrupção parece receber grande atenção dos veículos de comunicação, sendo uma constante pauta. Tampouco, são raros os episódios que envolvem trocas corruptas e que relacionam-se de maneira direta ao campo urbanístico e suas regulações. Acreditamos, entretanto, que a corrupção urbanística é um elemento ainda pouco abordado de maneira sistêmica e abrangente pela teoria do planejamento urbano. Distanciando-nos de enfoques que contemplam prioritariamente aspectos morais, interessa-nos neste estudo tratar de que maneira determinados desenhos de sistemas regulatórios podem determinar maiores possibilidades de trocas corruptas.

Os processos que envolvem a valorização do solo e suas transformações tornaram o urbanismo uma grande fonte de poder econômico (Singer, 1982). E esta capacidade está intimamente ligada na forma como ocorre o relacionamento com o poder público, de maneira que pode favorecer determinados sujeitos em detrimento de outros (Iglesias, 2007). São muitas as possibilidades econômicas decorrentes do parcelamento, uso e ocupação do solo. É neste campo, que possibilita a expansão das cidades, construção de edifícios, ocupação de imóveis com as mais variadas atividades econômicas, construção de infraestruturas, direcionamento de investimentos públicos, desapropriações e privatizações entre muitas outras questões ligadas ao solo. É neste mercado e nestas regulações que ocorrem os casos de corrupção urbanística.

Um sistema regulatório procura estabelecer limites para atividades privadas. A corrupção ocorre na medida em que determinados atores procuram burlar esses limites impostos por tal sistema, procurando agir de maneira diferenciada (Gardiner \& Lyman, 1978). Tais autores defendem que sistemas regulatórios que versam sobre o uso do solo, bem como regras para construção, possibilitam um extenso conjunto de oportunidades para trocas corruptas. Trocas desta natureza estariam, segundo Nye (1967), ligadas a um cálculo de custo-benefício, no qual atores racionais formulariam cenários, analisariam suas chances de sucesso e possíveis ganhos atuando à margem da lei, ponderando possíveis reveses ou punições.

Das modalidades de corrupção, frente aos estudos desenvolvidos (Gardiner \& Lyman, 1978; Alcaraz Ramos, 2007; Iglesias, 2007; Villoria \& Oset, 2007; Cappelletti, 2012; Transparency International, 2013; Chiodelli \& Moroni, 2015; Prestes, 2017) a corrupção urbanística destaca-se como uma das mais notáveis, permeando nossas cidades e interferindo na vida de seus habitantes. Alguns estudos (Cappelletti, 2012; Chiodelli \& Moroni, 2015) procuram estabelecer uma relação causal, apontando elementos presentes no desenho de determinados sistemas regulatórios como responsáveis por um aumento de trocas corruptas no campo urbanístico, ou seja, a forma como estes sistemas são estruturados poderia determinar quantitativamente um nível de corrupção nestes ambientes. Outros estudos (Warren, 2004; AlcarazRamos, 2007), debruçam-se sobre consequências diretas destas trocas apontando redução das possibilidades de participação social em ambientes corruptos, aumento da desigualdade, a redução dos direitos políticos, custos sociais mais elevados e manutenção de mecanismos clientelistas. Além disso, o alcance das políticas públicas seria reduzido, na medida em que estas são formuladas e utilizadas para fins privados, criando ineficiências no setor público e privado. 
Nye (1967) defende que a corrupção além de tornar menos eficiente economicamente uma sociedade a desestabiliza politicamente, colocando em risco sua capacidade administrativa. Warren (2004) argumenta que sociedades democráticas modernas tendem a preferir decisões baseadas em processos com algum tipo de participação popular. Com isto, garante-se maior legitimidade dos atos governamentais, aumentando sua eficiência e estabilidade política. Se tais preceitos são negados, podese argumentar que nas cidades onde existe um alto grau de corrupção nos processos de planejamento e gestão pode-se levar à deslegitimação do sistema. Neste sentido, defende-se que a própria corrupção significa uma ameaça à democracia.

No Brasil, a falta de distribuição de renda juntamente com o acelerado processo de urbanização ocorrido preponderantemente na segunda metade do século XX, propiciou um conjunto de cidades socialmente desiguais, territorialmente segregadas e ambientalmente desequilibradas (Maricato, 2003). Segundo Rolnik (1997) e Alfonsin (2001), um dos elementos fundamentais neste processo foi a formulação de normas ligadas ao território urbano, acarretando em manutenção de privilégios, concentração de poder e controle do território. Tais processos de formulação de leis, aprovação de projetos, concessão de licenças, alvarás e benefícios, frequentemente são apontados como tendo relação com práticas corruptivas (Cappelletti, 2012).

Alterações normativas podem ser vantajosas para empreendedores que contam com a valorização do solo. Frequentemente, o processo que determina quais áreas serão incorporadas à zona urbana não se baseia em critérios técnicos e estudos de viabilidade, uma vez que as administrações municipais atuaram como facilitadoras: modificando este status mediante a argumentação de viabilidade econômica feita por empreendedores (Sparovek et al., 2004). Neste sentido, argumenta Pera (2016), que mesmo onde não há a real necessidade de criação de novas áreas à zona urbana, persiste a criação de empreendimentos por todo o país mediante a anuência do poder público, beneficiando assim atores ligados ao mercado imobiliário.

A possibilidade do retorno financeiro ao se converter terra rural em urbana, aumentar o potencial construtivo de um terreno ou obter uma autorização para determinada atividade econômica em um imóvel, entre outras, pode ser tão alta que se transforma em um incentivo para que determinado ator busque provocar alterações das regras. Quase como se a corrupção pudesse provocar uma espécie de outorga onerosa do direito de construir ${ }^{1}$, cujo pagamento da contraprestação seria a propina, paga a algum funcionário público ou político com o poder de realizar tal alteração.

O sistema federativo brasileiro impõe uma contradição de autonomia entre entes, que se por um lado confere força ao poder local - o que favorece a diversidade regional dada a dimensão continental e heterogeneidade do pais - por outro, a autonomia municipal para tratar de questões relativas ao uso do solo, mostra-se vulnerável dada a proximidade das oligarquias locais ${ }^{2}$ ao poder publico municipal. $\mathrm{Na}$ criação e aplicação de normas, os interesses de grupos privados que detém proximidade com atores políticos seriam beneficiados.

Para Gardiner \& Lyman (1978), a dinâmica entre corrupção e um determinado sistema de planejamento e gestão urbanos estaria diretamente ligada a questões regulatórias locais, que seriam influenciadas pelas formas política de governo e a sua respectiva estrutura administrativa. Para compreender a corrupção em uma cidade, seria necessário entender seus sistemas regulatórios. Os autores afirmam que o fato de existir ou não corrupção em uma comunidade seria uma consequência de como esta mesma comunidade responderia a estes incidentes. Algumas seriam mais tolerantes e outras, menos. Nestas comunidades onde a ocorrência é menor, mecanismos criados para a prevenção destes comportamentos seriam mais abrangentes e sofisticados do que nas cidades onde a corrupção seria mais tolerada.

\footnotetext{
${ }^{1}$ Outorga Onerosa do Direito de Construir é um instrumento de política urbana definido no Estatuto da Cidade (10.257/2001). Por meio dele, é possível construir acima dos limites estipulados para determinado local, mediante pagamento de uma contrapartida.

${ }^{2}$ Utilizamos neste trabalho o termo oligarquia para descrever certos grupos que dominam estruturas de poder, conduzindo seus negócios de maneira privilegiada, apoiados em uma relação de proximidade à burocracia estatal. Estes grupos, frequentemente pela posse de algum ativo estratégico como o controle da terra, apresentam sobre a população local uma forma de domínio, condicionando o acesso da mesma ao mercado e à dinâmica política às suas vontades (Leal, 1948).
} 
A presença do poder público nas dinâmicas corruptivas ligadas ao planejamento e gestão urbanos se deve a sua capacidade de produzir e aplicar regras que limitam ou condicionam a atuação de agentes privados neste mercado. 0 poder público pode definir regras e limites para parcelamento, construção e uso do solo, estando dissociados do direito de propriedade. Muitas vezes a corrupção urbanística interfere nesta dinâmica, atenuando ou mesmo extinguindo tais limites à propriedade privada.

\section{Estrutura da corrupção urbanística}

A definição do termo "corrupção" utilizado neste trabalho consiste no desvio de condutas de agentes públicos, possibilitando benefícios privados: sejam eles, materiais ou imateriais (Nye, 1967; Bardhan, 1997) ou a quebra de regras para que influências privadas sejam exercidas (Banfield, 1961).

Chiodelli \& Moroni (2015) propuseram uma estrutura para analisar a corrupção urbanística. Segundo os autores, entre as diferentes práticas existentes, prevaleceriam três formas principais. Em primeiro, estaria a corrupção regulatória ou legislativa: legisladores seriam influenciad os mediante pagamento de propina para estabelecer regras favoráveis a determinados sujeitos. Num nível secundário estaria a corrupção burocrática, ligada ao desvio de condutas de funcionários públicos. Estes poderiam favorecer determinados indivíduos por meio de fornecimento de licenças, tratamento diferenciado ou procedimentos acelerados em troca de bens materiais ou imateriais. No terceiro nível estariam os casos relacionados a desvios em obras e serviços públicos, como superfaturamentos e fraudes em licitações.

Para que se possa entender de que forma a corrupção urbanística se organiza, é necessário entender sua dinâmica, vetores e dimensões onde ela se desenvolve. Para tanto, utilizaremos uma estrutura compilada por Cappelletti (2012) unindo três elementos fundamentais elencados por Savona \& Mezzanotte (1998) e um quarto sugerido por Della Porta \& Vannucci (1994): a) os setores que são afetados pela corrupção; b) os agentes que desempenham um papel nas transações; c) os métodos, os instrumentos e mecanismos utilizados; d) os recursos trocados ilegalmente pelo agente público.

\section{Setores afetados pela corrupção}

Cappelletti (2012), afirma que em um ambiente onde o mercado é regulado, poderiam ocorrer influências em determinados setores, influenciados por meio do que o autor define como poderes estatais: o poder de licenciar, na medida em que um representante do Estado influi sobre um bem privado; o poder de investimento, quando o Estado como principal ou único investidor decide sobre investimentos e obras públicas; o poder de financiar, cabendo ao Estado determinar as condições para acesso ao crédito, frente às opções do mercado. Dentro desta lógica, os setores afetados pelas dinâmicas corruptivas seriam: obras públicas, auxílio e cooperação internacional, processos de privatização, processos de definição de uso do solo, concessões e licenças, atividades de controle e regulamentação, atividades de polícia, atividades jurídicas, venda de votos e licitações públicas.

Atores

Atem-se neste estudo à tipologia definida pela literatura de referência (Gardiner \& Lyman, 1978; Rose-Ackerman, 1978; Nye, 1967), em que existiriam dois papéis principais e ao mesmo tempo complementares: corrupto e corruptor. Lambsdorff (2002) inclui a possibilidade de um agente intermediário nestas relações, de modo a facilitar sua interação, ao mesmo tempo em que diminuiria os 
riscos para ambos os atores, evitando sua exposição. Gardiner \& Lyman (1978) propuseram uma definição para corrupção que enquadraria propina (quando iniciada pelo corruptor) e extorsão (quando iniciada pelo funcionário público). Cappelletti (2012) argumenta que no campo urbanístico os atores corruptos seriam, funcionários públicos de todos os níveis, desde que pudessem aplicar decisões administrativas com algum grau de poder discricionário. Os corruptores, segundo o autor, iriam desde cidadãos comuns que por meio da corrupção pretenderiam burlar normas ou conseguir alguma forma de privilégio utilizando a estrutura administrativa estatal até grandes empresas que, por meio destas práticas, tentassem diminuir a concorrência de mercado.

\section{Métodos, instrumentos e mecanismos}

A dinâmica de um sistema corrupto no campo urbanístico está ligada frequentemente à interação de elementos, que atuando em menor ou maior escala, potencializam a oportunidade de trocas corruptas. Estas interações, tendo um elemento maior preponderância sobre os outros, dependem de características específicas locais como a estrutura administrativa do governo, as dinâmicas políticas locais e os mecanismos de controle instituídos. As pressões econômicas locais influenciam diretamente sobre as políticas urbanísticas, determinando reflexos sobre toda a população (Cappelletti, 2012). Foram selecionados três elementos que se consideram importantes frente à literatura que trata da corrupção urbanística:

\section{Alta discricionariedade}

Segundo Chiodelli \& Moroni (2015) a possibilidade de tratar de maneira diferenciada dois locais de um mesmo território seria um fator que potencializaria a criação de oportunidades para trocas corruptas. Ser possível criar regras diferentes para locais semelhantes acarretaria possibilidades econômicas diversas. A questão a ser observada é a maneira como estas regras seriam definidas e a forma como elas são aplicadas. A alta discricionariedade administrativa dos agentes públicos em um determinado sistema é um fator que pode levar a um aumento de oportunidades de trocas corruptas. A possibilidade de concentrar a tomada de decisões específicas nas mãos de poucos atores pode tornar estes, mais sujeitos a buscarem ganhos ilegais, oferecendo vantagens ligadas às suas decisões para atores interessados em obter benefícios, facilitados pela corrupção.

\section{Opacidade}

Parte da literatura aponta a falta de transparência nos procedimentos como fator que potencializa a corrupção (Gardiner \& Lyman, 1978; Rose-Ackerman, 1978; Klitgaard, 1988; Kaufmann, 2005; Bardhan, 2006; Cappelletti, 2012). 0 controle por um grupo pequeno de atores de dados, informações, normas e procedimentos reduz a isonomia de tratamento dada pelo poder público aos cidadãos. Isto significa que serão privilegiados aqueles que obtiverem determinado tipo de informação que diga respeito aos processos de planejamento e gestão. Isto se traduziria em maiores ganhos econômicos, visto que esta seria uma vantagem competitiva, frente aos concorrentes. Assim, seria possível realizar procedimentos de maneira acelerada, sabendo-se de antemão de futuras mudanças normativas que tornaria empreendimentos irregulares ou menos lucrativos. Dessa maneira, seria possível protocolar projetos construtivos utilizando-se, por exemplo, de coeficientes de aproveitamento mais favoráveis, ou iniciar o parcelamento em áreas que futuramente exigiriam maiores contrapartidas dos empreendedores.

Prestes (2017) argumenta ainda que o controle de informações também pode determinar assimetrias procedimentais por servidores públicos. Quando certas regras não são claramente estabelecidas, alguns atores conseguiriam obter vantagens na análise de projetos, criando obstáculos para aqueles que não se dispuseram a pagar propina, ao mesmo tempo oferecendo um trâmite acelerado para os que pagaram. 
Neste caso, percebe-se a dinâmica em que a alta discricionariedade e baixa transparência atuam juntas para potencializar a corrupção.

\section{Imprecisão e direcionamento normativo}

Outro fator que autores que tratam da corrupção no campo urbanístico (Cappelletti, 2012; Chiodelli \& Moroni, 2015), causada pelo desenho do sistema de planejamento, consiste na importância para o aumento das oportunidades de corrupção nos sistemas de planejamento e gestão urbanos na maneira com que normas podem ser redigidas de modo a fomentar a discricionariedade ou determinar privilégios para alguns atores. A imprecisão normativa pode gerar ambivalência interpretativa nos processos de planejamento. Redações com alto grau de subjetividade podem representar um risco em sua aplicação, possibilitando brechas para atuações de grupos de interesse e, ficando o gestor público exposto à influência destes.

Dessa maneira, é possível perceber como estes três elementos atuam conjuntamente e em diferentes níveis, dependendo das características administrativas de um sistema, para potencializar oportunidades de corrupção nos sistemas de planejamento e gestão. Salientamos que não queremos com isso descartar outros elementos ${ }^{3}$ ou diminuir a importância destes, tampouco criar um modelo estático que possa ser aplicado de maneira geral. Nosso intento aqui é exibir algumas dinâmicas possíveis, para que o leitor possa fazer aproximações de acordo com os elementos empíricos coletados.

\section{Recursos trocados ilegalmente}

Quando trata-se da forma como recursos são trocados em transações corruptas, é preciso lembrar que estamos lidando com uma realidade muito específica. Lambsdorff (2002) afirma que a natureza das trocas corruptas difere das trocas legais pela necessidade de ocultar sua existência. Além disso, os partícipes ao fim destas operações possuiriam informações potencialmente comprometedoras mutuamente.

Isto significa que são características destas trocas um alto grau de confidencialidade (controle da divulgação de informações), grande opacidade (a não detecção dos processos ou de parte deles por atores externos) e a participação limitada dos atores (controle sobre aqueles que participam das transações).

Desta dinâmica, em que o controle parece ser a peça chave do sistema, é importante lembrar que os atores envolvidos carregam informações suficientes para prejudicar seu interlocutor, não terminando após o fim do serviço e o respectivo pagamento (Lambsdorff, 2002).

0 autor argumenta que a definição das contrapartidas é um elemento que pode dificultar a detecção dos bens utilizados nas trocas. Frequentemente, procedimentos legais são utilizados para eludir formas de controle, mascarando assim a natureza destas transações como presentes e empréstimos. Formas imateriais seriam também utilizadas como o convite para ingressar em sociedades e grupos de prestígio ou eventos exclusivos para mascarar pagamentos de propina.

\section{Estudo de caso: São João da Boa Vista (1985-2016)}

A identificação de processos corruptivos no campo urbanístico não é tarefa simples. Como toda atividade corrupta, sua natureza é a de ocultar seus rastros por meio de procedimentos que envolvem,

\footnotetext{
${ }^{3}$ Prestes (2017, p. 339), cita como elementos importantes a desregulamentação, lentidão do processo administrativo, falta de estruturas compatíveis com a gestão e a quantidade de normas a serem atendidas. Gardiner \& Lyman (1978, p. 145) e Cappelletti (2012, p. 177), listam o poder das decisões administrativas para criar "benefícios" privados, a congruência com outras políticas públicas já instituídas que possibilitariam estas trocas, o reduzido número de indivíduos partícipes das decisões e a proximidade social entre atores corruptos como fatores potencializadores da corrupção urbanística.
} 
de maneira individual ou combinada, alterar a natureza destes, "legalizando o que é ilegal"; diminuir a quantidade de indivíduos que podem ter acesso a documentos que detalham tais procedimentos, reduzindo a transparência destas operações e alterando a percepção da natureza destes atos, muitas vezes criando discursos que levem a própria população a legitimar estas práticas; determinar mecanismos onde regulamentos são vazios propositalmente de modo a permitir que atores tenham sua atuação ampliada e sua responsabilidade diminuída, dependendo da conveniência do momento.

Neste trabalho, o foco é período entre os anos 1985 e 2016. Tal corte temporal se deve à relevância das modificações ocorridas: o processo de redemocratização do país, a implantação de um novo paradigma legal baseado na Constituição Federal de 1988, a expansão territorial urbana, o surgimento de novas tipologias espaciais e a criação de instâncias participativas com o intuito de interferir nos processos de planejamento e gestão urbanos.

A forma como esta dinâmica acontece sobre o território não pode ser entendida completamente se não analisarmos o modo como ele é administrado e quais são os mecanismos presentes. Para tanto, não basta entender como a expansão de um município ocorre do ponto de vista de sua distribuição espacial. É preciso descrever os processos, compreendendo o papel e a importância de seus atores. Para isso, serão detalhadas a seguir as estruturas presentes nos processos de expansão urbana.

\section{Método e procedimentos}

O estudo empírico de práticas corruptivas possui limitações metodológicas conhecidas, ligadas principalmente à natureza e alcance de informações documentais (Ades \& Di Tella, 1997). Em sistemas de Planejamento e Gestão Urbanos, diferentes partes dos processos podem estar envolvidas com tais práticas, o que aumentaria a complexidade dos levantamentos documentais (Chiodelli, 2018).

O Método adotado parte da análise qualitativa dos documentos analisados, isto é, tem como ponto de partida documentos que apontam os fatos e suas características. As categorias de analises adotadas buscam identificar fatores indutores da corrupção urbanística como: a alta discricionariedade, a opacidade procedimental e o direcionamento normativo. A análise qualitativa permite delinear procedimentos e parâmetros dos sistemas de Planejamento e Gestão Urbanos vigentes no município com potencial de fomentar a corrupção urbanística.

Toma-se como procedimento metodológico:

O levantamento:

- Da estrutura político-administrativa ligada ao sistema de planejamento e gestão urbano;

- Da legislação pertinente;

- Do desenho institucional municipal.

Tomando como amostra um processo administrativo concreto é possível analisar:

- As circunstâncias específicas e instâncias de aprovação;

- 0 estabelecimento de relações entre elementos descritos na literatura que trata da corrupção urbanística e dos resultados da análise empírica.

Desta maneira, foi possível estabelecer quais ritos processuais e instâncias decisórias estavam presentes no sistema em questão e relaciona-los com os mecanismos acima apontados (alta discricionariedade, opacidade procedimental, imprecisão e direcionamento normativos). Ao mesmo tempo, mapeou-se a expansão do município no período, por meio do levantamento e sistematização de todos os loteamentos aprovados. Diante dos resultados, foi possível determinar grupos empresariais presentes na expansão urbana neste período, localizar e quantificar seus empreendimentos e estabelecer quais eram os atores ligados a estes grupos. 
Para determinar quais processos administrativos possibilitam obtenção de vantagens privadas, utilizamos como amostra um processo administrativo para loteamento do grupo empresarial que executou maior quantidade de loteamentos neste período. Ao analisar as instâncias de aprovação deste processo, frente ao desenho institucional municipal, foi possível determinar laços entre atores estatais e privados dentro de uma lógica de favorecimento para grupos empresariais que participavam ativamente dos processos decisórios do sistema de planejamento e gestão do município por meio de uma comissão. Através do estabelecimento de relações entre elementos descritos na literatura que trata da corrupção urbanística e dos resultados da análise empírica, foi possível determinar de que maneira algumas características presentes em um sistema de planejamento e gestão urbano podem possibilitar trocas corruptas.

\section{Estrutura administrativa municipal}

A macroestrutura administrativa de São João da Boa Vista, pode ser dividida em dois níveis principais. No nível mais externo, existem onze departamentos municipais, chefiados por diretores nomeados politicamente, ocupando cargos de livre-provimento, que respondem diretamente ao prefeito. Em cada departamento, questões de uma ou mais áreas setoriais são tratadas por equipes técnicas compostas por servidores públicos concursados e funcionários em cargos comissionados.

No nível central, estão os setores que assessoram diretamente o prefeito. 0 gabinete do prefeito, que atua na representação social e política do chefe do poder executivo e mais quatro assessorias temáticas: jurídica, comunicação social, assuntos especiais e planejamento, gestão e desenvolvimento.

Nenhum destes departamentos e assessorias possui autonomia orçamentária. Seus empenhos são definidos anualmente no orçamento municipal. É o chefe do executivo quem autoriza gastos e realiza remanejamentos entre setores de acordo com sua conveniência.

O departamento responsável pela análise, formulação de diretrizes e aprovação de novos loteamentos é o Departamento de Engenharia. As condições e procedimentos para o parcelamento do solo urbano no município estão definidos na Lei Municipal 1.366 de 07 de julho de 2004 (São João da Boa Vista, 2004b). Nesta Lei, são admitidas duas modalidades de parcelamento: loteamento e desmembramento. Este parcelamento pode ocorrer exclusivamente em zonas urbanas ou de expansão urbanas.

Durante o período abordado, encontramos duas variações do trâmite que envolve a análise e aprovação de um loteamento. A primeira trata do trâmite "comum", a segunda, no chamado regime de aprovação antecipada. Essencialmente, a diferença entre estes tipos de processos de aprovação de loteamento urbano, se dá nos procedimentos de expedição da licença de obra e do decreto de aprovação. $\mathrm{Na}$ modalidade de aprovação antecipada, mediante apresentação de garantias pelo requerente à administração municipal, a publicação do decreto de aprovação ocorre simultaneamente à expedição da licença de obra. Isto significa que o loteador pode individualizar os lotes e comercializá-los enquanto realiza obras de infraestrutura. Na modalidade comum, a comercialização só é permitida após a emissão do decreto de aprovação, ao final das obras civis do loteamento.

A Lei de Parcelamento do Solo ainda estabelece em seu artigo 8oㅡ, a obrigação para que a Prefeitura nomeie por decreto a chamada Comissão de Análise e Parcelamento de Solo do Município. No artigo 9o, estipula que a viabilidade ou não de todo loteamento será objeto de análise da referida comissão.

A composição desta Comissão foi estabelecida originalmente na Lei de Parcelamento do Solo (1.366/2004) e alterada por duas leis subsequentes (1.394 de 21 de setembro 2004 e 1.903 de 12 de setembro de 2006), conforme detalhamento existente na Tabela 1. Cada departamento municipal citado teria direito a um assento na comissão, bem como um indicado representando cada concessionária de serviço público relacionada à infraestrutura do município (transmissão de eletricidade, telefonia e saneamento), do CONDEMA (Conselho Municipal do Meio Ambiente), da Ordem dos Advogados do Brasil, da Câmara Municipal e de um "Grupo Ecológico".

São estes o panorama regulatório e os procedimentos principais que tratam do parcelamento de solo urbano no município de São João da Boa Vista. Como verificamos, existe grande centralização 
organizacional na figura do chefe do executivo. Ainda, os chefes de departamentos municipais em sua totalidade são indicados diretamente pelo prefeito, não havendo quesitos profissionais mínimos ou obrigatoriedade que a vaga seja ocupada por servidor concursado.

Observou-se que o departamento responsável pela formulação de diretrizes, análise e aprovação de projetos de parcelamento do solo urbano é o Departamento Municipal de Engenharia. Nota-se também, ao analisar o arcabouço legal do município concernente à esta matéria, que existe uma segunda instância responsável pela formulação de diretrizes, análise e aprovação de projetos de parcelamento do solo urbano chamada de Comissão de Análise e Parcelamento de Solo e que seu presidente é o Diretor do Departamento de Engenharia. Esta comissão não possui regulamentos que regem seu funcionamento, apenas sendo definidos em lei os assentos a serem ocupados por um rol de departamentos municipais e entidades da sociedade civil.

A seguir, debruça-se sobre algumas dinâmicas que levaram à elaboração dos marcos regulatórios municipais que tratam do parcelamento de solo urbano. Veremos também de que forma o funcionamento desta Comissão operou na expansão de áreas urbanas do município.

\section{O Episódio Morro Azul e uma lei de parcelamento do solo sob medida}

A expansão da área urbana de São João da Boa Vista, no período abordado neste estudo, foi regida por duas leis municipais. A primeira, Lei Municipal de Parcelamento (01/1982), que não apresentava inovações frente à Lei Federal 6.766/79, tendo um papel meramente formal na regulamentação de uso do solo. A segunda, e alguns desdobramentos correlatos, serão analisadas a seguir.

Morro Azul foi o primeiro loteamento protocolado no município com intenção de se estabelecer na forma fechada. Em 3 de julho de 2001, foi endereçado um ofício ao prefeito, solicitando ao Grupo de Estudos e Análise de Loteamentos parâmetros necessários para implantação deste empreendimento (São João da Boa Vista, 2001). A resposta foi dada uma semana depois, definindo além de algumas diretrizes viárias, que toda a infraestrutura urbana deveria seguir a Lei de Parcelamento vigente à época.

Em 24 de agosto de 2001 um novo ofício foi endereçado ao prefeito, solicitando aprovação de diretrizes e a certidão de uso e ocupação do solo, para que se desse continuidade com o projeto do condomínio em questão. 0 responsável técnico pelo projeto urbanístico seria um dos membros do mesmo Grupo de Estudos e Análise de Loteamentos, instância de apreciação de novos loteamentos (São João da Boa Vista, 2001).

Como ainda nenhum empreendimento semelhante existia na cidade, não havia parâmetro algum que pudesse nortear sua tramitação, já que a Lei Federal de Parcelamento do Solo no 6.766/79 não contempla esta modalidade fechada. A primeira tentativa foi utilizar a Lei Federal no 4.591/1964, que trata do regime de propriedade em condomínios, para fins de parcelamento urbano (São João da Boa Vista, 2001).

Aprovadas as diretrizes viárias pelo prefeito e pelo diretor do Departamento de Engenharia, ainda restavam algumas questões que seriam sanadas posteriormente. Não havia definição de como as áreas institucionais se comportariam em um loteamento fechado. Nem a Lei Federal 6.766/79 e tampouco a Lei Municipal de Parcelamento (01/1982) previam esta questão.

Dois anos mais tarde, com o processo ainda em tramitação, a Prefeitura promoveu uma série de reuniões de estudos onde participaram representantes do Departamento de Engenharia, Assessoria Jurídica do Município, Câmara Municipal, Associação dos Engenheiros, Cartório de Registro de Imóveis e de empresas loteadoras do município. Destas reuniões, resultou Projeto de Lei encaminhado pelo prefeito à Câmara, sob a justificativa que "[...] as alterações propostas neste projeto são provenientes da Associação dos Engenheiros e do Cartório de Registro de Imóveis, com relação a lei de loteamento fechado" (São João da Boa Vista, 2004a, p. 16).

Após sofrer emendas na Câmara, a nova Lei Municipal de Parcelamento do Solo foi aprovada sob noㅡ 1.366 em 07 de julho de 2004. 0 novo texto trazia um capítulo específico sobre loteamentos fechados, discriminando todo o processo de aprovação deste tipo de empreendimento incluindo a adoção de 
regulamentos internos, a criação de uma associação de proprietários e como tal associação poderia pleitear uma concessão do uso de áreas públicas para uso privado e exclusivo dos moradores. Além disso, possibilitava ao loteador a transferência de áreas institucionais para outros pontos da cidade, por meio de pagamento feito ao município, deixando o loteamento em questão desprovido das mesmas. Houve ainda mais uma emenda neste capítulo, determinando que depois de registrado no Cartório de Registro de Imóveis como loteamento fechado, em hipótese alguma o mesmo poderia se converter em loteamento aberto. Neste processo, evidenciam-se indícios de direcionamento normativo bem como aumento da discricionariedade.

Outra novidade que a Lei de Parcelamento do Solo trazia era a instituição de uma Comissão de Análise e Parcelamento do Solo, substituindo o antigo Grupo de Estudos e Análise de Loteamentos. Esta comissão, a partir de agora referindo-se a ela como CAPS, seria formada por representantes listados na Tabela 1. Além desta composição, um representante de cada concessionária de serviço público também poderia participar, com direito a voto.

Tabela 1 - Variações de integrantes da Comissão de Análise e Parcelamento de Solo

\begin{tabular}{ccc}
\hline LEl 1366/2004 & LEl 1394/2004 & LEl 1903/2006 \\
\hline Engenharia & Diretor Engenharia & Diretor Engenharia \\
Topografia & Topografia & Topogria \\
Planejamento & Planejamento & Planejamento \\
Conselho Meio Ambiente & Conselho Meio Ambiente & Conselho Meio Ambiente \\
Câmara Municipal & Câmara Municipal & Câmara Municipal \\
Associação Engenheiros, Arquitetos e & Associação Engenheiros, Arquitetos e & Associação Engenheiros, Arquitetos e \\
Agrônomos & Agrônomos & Agrônomos \\
OAB & OAB & OAB \\
Grupos ecológicos & Grupos ecológicos & Grupos ecológicos \\
Concessionárias serviços públicos & Concessionárias serviços públicos & Concessionáncia sanitária serviços públicos \\
\hline
\end{tabular}

Fonte: Trabalho dos autores sobre dados da Prefeitura Municipal (São João da Boa Vista, 2004b, 2004c, 2006a).

Promulgada a nova lei, seguiu-se novo processo para aprovação do loteamento fechado Morro Azul (São João da Boa Vista, 2005). Desta vez, já citando a nova lei, o empreendedor solicitava a conversão de "condomínio" em "loteamento fechado", e citando a respectiva área institucional a ser doada ao município. A escolha desta área se localizava diametralmente oposta ao empreendimento: se este estava no limite leste da mancha urbana, a área estava no limite sudoeste. A modificação normativa que possibilitou a aprovação do loteamento referido evidencia uma situação de direcionamento normativo.

Durante o decorrer do processo, aprovações na CAPS contaram com a presença do engenheiro civil autor do projeto, responsável técnico, procurador contratado pela empreendedora (São João da Boa Vista, 2004d, 2005) evidenciando além de um possível conflito de interesses, indícios de alta discricionariedade.

Ao final do trâmite, um decreto foi expedido aprovando o loteamento e cedendo a permissão das áreas públicas localizadas dentro do loteamento (São João da Boa Vista, 2006b, 2010) para a AMORAZUL Associação dos Moradores do Morro Azul, criada em 18 de setembro de 2004, poucos meses após a aprovação da nova Lei de Parcelamento do Solo.

\section{Relações entre agentes estatais e privados}

Em dezembro de 2016, representantes do Ministério Público e da Polícia Civil realizaram buscas, apreendendo materiais e documentos em empresas loteadoras e departamentos da Prefeitura de São João da Boa Vista. A chefe da Assessoria Jurídica foi afastada de suas funções, sendo investigada por possíveis irregularidades na aprovação de loteamentos. 0 promotor declarara a época que "[...] ela facilitava liberações, agilizava processos e tinha o poder de mando para várias situações envolvendo as loteadoras da cidade" (Gasparino, 2017a, p. 8), caracterizando desta maneira uma forma de diferenciação 
procedimental nos processos de expansão urbana (Gardiner \& Lyman, 1978; Chiodelli \& Moroni, 2015; Prestes, 2017). Além disso, salientou que a chefe da assessoria jurídica advogava por meio de seu escritório particular para o Centro Universitário UNIFAE, uma autarquia municipal que já possuía um corpo jurídico estabelecido.

Observando a composição societária do referido escritório de advocacia é possível estabelecer outros vínculos com as empresas loteadoras. Seu sócio, filho do ex-prefeito responsável por sua nomeação, aparece como proponente de um pedido de loteamento protocolado na cidade e na época, em análise, caracterizando mais um indício de diferenciação procedimental.

A advogada foi nomeada no dia 1/01/2005, tendo permanecido no cargo comissionado até o dia 01/12/2016. Neste período, teria recebido, de acordo com o inquérito do Ministério Público, a título de honorários advocatícios em Ações de Execução Fiscal do município a quantia de R \$369.331,54. Tal recebimento, segundo a denúncia, não teria qualquer previsão jurídica ou estatutária. Este tipo de remuneração seria possível apenas aos procuradores municipais, funcionários concursados com cargos efetivos, seguindo carreira própria (Gasparino, 2017b).

Ao analisar os documentos apreendidos, a promotoria elencou e-mails em que a Chefe da Assessoria Jurídica se reportava a donos de empresas loteadoras dizendo que estava intercedendo junto a departamentos municipais para conseguir documentos e informações para que denúncias de irregularidades em loteamentos realizadas por cidadãos, pudessem ser arquivadas, caracterizando alta discricionariedade e opacidade procedimental. O Ministério Público também demonstrou os pedidos que ela realizara para departamentos da prefeitura (Oliveira, 2017) .

Além disso, um contrato de permuta foi anexado ao inquérito. Nele a advogada e marido realizavam uma operação imobiliária onde trocavam com donos da loteadora (Grupo Empresarial 1, Tabela 2) um apartamento de médio padrão e dois lotes por uma casa na região central. 0 texto dizia que a diferença seria um valor de $\mathrm{R} \$ 130.000,00$, que poderia ser paga da maneira que fosse conveniente, nos próximos cinco anos. Condições semelhantes às descritas na literatura de referência (Lambsdorff, 2002).

Tabela 2 - Loteamentos aprovados (2000-2015)

\begin{tabular}{|c|c|c|}
\hline EMPRESA & ANO & LOTEAMENTO \\
\hline \multirow[t]{20}{*}{ Grupo empresarial 1} & 2000 & |pês || \\
\hline & & Maestro Mourão \\
\hline & 2001 & Jardim das Flores \\
\hline & & Santa Águida \\
\hline & & Jardim Yolanda \\
\hline & 2003 & |pês || \\
\hline & 2004 & Lucas Teixeira \\
\hline & 2005 & Flamboyant \\
\hline & & Serra da Paulista \\
\hline & 2006 & Morro Azul* \\
\hline & 2009 & Morro Azul II* \\
\hline & 2010 & Monte Verde \\
\hline & & Fazenda das Areias \\
\hline & & Jardim Yara \\
\hline & & Lago da Prata* \\
\hline & 2011 & Jardim Belvedere \\
\hline & & Portal das Mangueiras \\
\hline & & Recanto da Serra \\
\hline & 2012 & Jardim das Rosas \\
\hline & & Parque das Bromélias \\
\hline
\end{tabular}


Tabela 2 - Continuação...

\begin{tabular}{|c|c|c|}
\hline EMPRESA & ANO & LOTEAMENTO \\
\hline \multirow{12}{*}{ Companhia de Desenvolvimento Habitacional e Urbano (CDHU) } & & Serra do Prata* \\
\hline & 2013 & Portal da Aliança I \\
\hline & 2014 & Portal da Serra* \\
\hline & 2015 & Alvorada \\
\hline & & Macaubeiras* \\
\hline & 2011 & Jardim das Tulipas \\
\hline & 2012 & Jardim das Acácias \\
\hline & 2014 & Pôr do Sol \\
\hline & 2015 & Jardim Aurora \\
\hline & & Nova União \\
\hline & 2009 & Recanto do Jaguari \\
\hline & 2011 & Hortências \\
\hline \multirow[t]{8}{*}{ Prefeitura Municipal } & 2000 & Jardim América do Sul \\
\hline & 2006 & Jardim Europa \\
\hline & 2008 & Distrito Industrial (ampliação) \\
\hline & 2009 & Azaléias \\
\hline & 2010 & Amoreiras \\
\hline & & Amoreiras II \\
\hline & 2012 & Resedás \\
\hline & 2013 & Distrito Industrial ( $4^{a}$ etapa) \\
\hline \multirow[t]{3}{*}{ Grupo empresarial 3} & 2002 & Jardim do Trevo \\
\hline & 2007 & Recanto das Águas \\
\hline & 2014 & Colinas do Alegre \\
\hline Grupo empresarial 4 & 2013 & Valle do Prata* \\
\hline Grupo empresarial 5 & 2000 & Dona Teresa II \\
\hline Sindicato & & Comerciários \\
\hline Grupo empresarial 6 & 2002 & Riviera de São João \\
\hline \multirow[t]{3}{*}{ Grupo empresarial 7} & & Terras de São José \\
\hline & 2003 & Recanto dos Pássaros II \\
\hline & 2014 & Alto da Paulista \\
\hline \multirow[t]{3}{*}{ Grupo empresarial 8} & 2013 & Jd. dos Jacarandas 1 \\
\hline & & Jd. dos Jacarandas 2 \\
\hline & & Vista da Serra* (desmembramento) \\
\hline
\end{tabular}

*Indica loteamento fechado. Relação de loteamentos aprovados no período de 2000-2015, organizados por grupos de empresas loteadoras. Por utilizarem-se frequentemente de diferentes nomes para cada loteamento, optou-se pelo agrupamento, demonstrando-se assim quais são os grupos dominantes no mercado. Fonte: Levantamento e compilação realizados pelos autores sobre dados Viva São João (2014) e São João da Boa Vista (2016).

Estas informações compõem um quadro extremamente plausível de atuação entre atores públicos e privados, utilizando-se do aparato público para conseguir benefícios privados para ambos e ao mesmo tempo, limitando a concorrência por meio da concessão de privilégios. 


\section{Resultados}

A partir do levantamento e sistematização de dados sobre os loteamentos aprovados na cidade, elaboramos uma Tabela (Tabela 2) agrupando os empreendimentos de acordo com suas empresas responsáveis, o que será chamado a seguir de grupos empresariais. Esta Tabela contém todos os loteamentos aprovados no período entre 2000 e 2015 no município, sendo suas localizações especializadas na Figura 1.

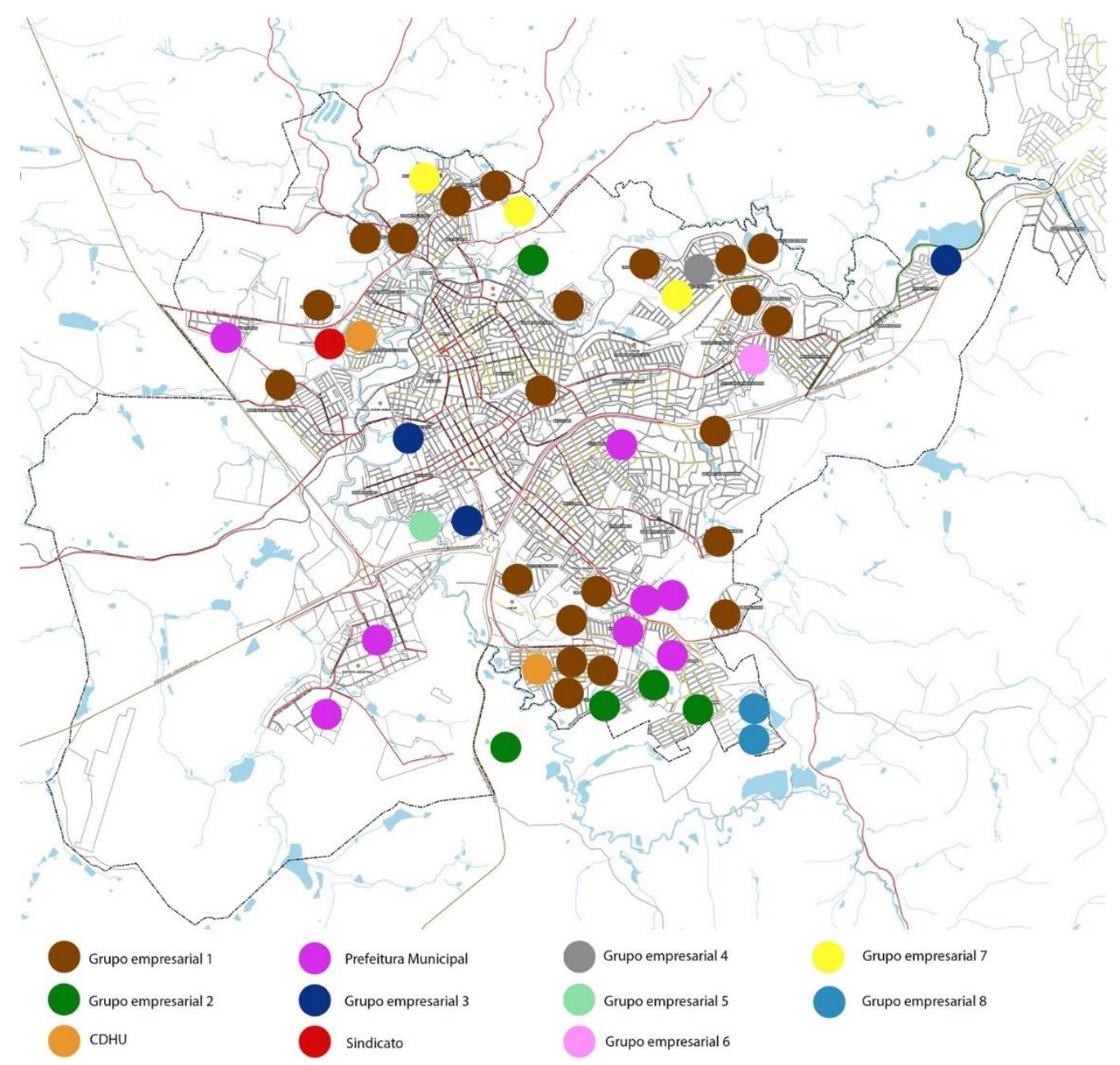

Figura 1 - Distribuição espacial de loteamentos aprovados no período de 2000-2015. Loteamentos identificados por cores representando seus respectivos grupos empreendedores (cf. Tabela 1). Fonte: Interferência dos autores sobre mapa de vias do Plano Diretor - Prefeitura de São João da Boa Vista, 2006.

De acordo com o levantamento realizado, analisando as empresas interessadas e seus empreendimentos (Tabela 2), constatou-se que agentes ligados ao mercado imobiliário participaram de diversas aprovações ligadas à expansão urbana por meio da CAPS. Mais especificamente, encontramos funcionários que trabalhavam em dois grupos empresariais, listados como Grupo Empresarial 1 e 2 (Tabela 2).

Além disso, pôde-se constatar, ao analisar a quantidade de loteamentos executada neste período, que coincidentemente estes dois grupos econômicos concentram o maior número de empreendimentos. Tendo, ambos os grupos, participado nesta instância por 11 anos ininterruptos (2004-2015). Isto significa que o Grupo Empresarial 1 participou de dezenove aprovações de projetos de sua autoria e o Grupo Empresarial 2, de cinco projetos de sua autoria.

A possibilidade de participação destes representantes nesta instância deliberativa favorece ações ligadas ao controle de território e de corrupção urbanística como: agilizar procedimentos, minimizar 
questões problemáticas ou mesmo constranger questionamentos de outros membros pela simples presença destes indivíduos.

Cabe destacar o fato de que o mesmo engenheiro civil responsável técnico pelo processo pôde participar de uma instância de aprovação em diversas ocasiões, nomeado por portaria pelo prefeito para participar da CAPS, evidenciando-se assim uma situação de conflito de interesses, potencializada pela alta discricionariedade.

Estas reuniões aconteciam sem regimento interno e com baixa publicidade de seus processos decisórios, divulgando-se apenas súmulas resumidas. Caracteriza-se, portanto, a opacidade procedimental assim como um compartilhamento assimétrico de informações ao mesmo tempo em que possibilitavam a manutenção de privilégios de atores interessados neste mercado, dificultava o controle por parte de concorrentes, órgãos de controle e sociedade civil. Como afirma Cappelletti (2012), uma parte possuindo maiores ou melhores informações do que outra poderia influenciar o processo como um todo. Além disso, o poder de informações privilegiadas se refletiria em um maior poder econômico, gerando distorções no próprio mercado.

Ao observarmos a Figura 2, é possível relacionarmos quais entidades estes atores e representavam nesta comissão: Assessoria de Planejamento Municipal, Conselho de Meio Ambiente (CONDEMA), Associação dos Engenheiros e Câmara Municipal. Cabe destacar que esta representação gráfica equivale à determinada composição segundo Portaria Municipal 8.376 (São João da Boa Vista, 2014).

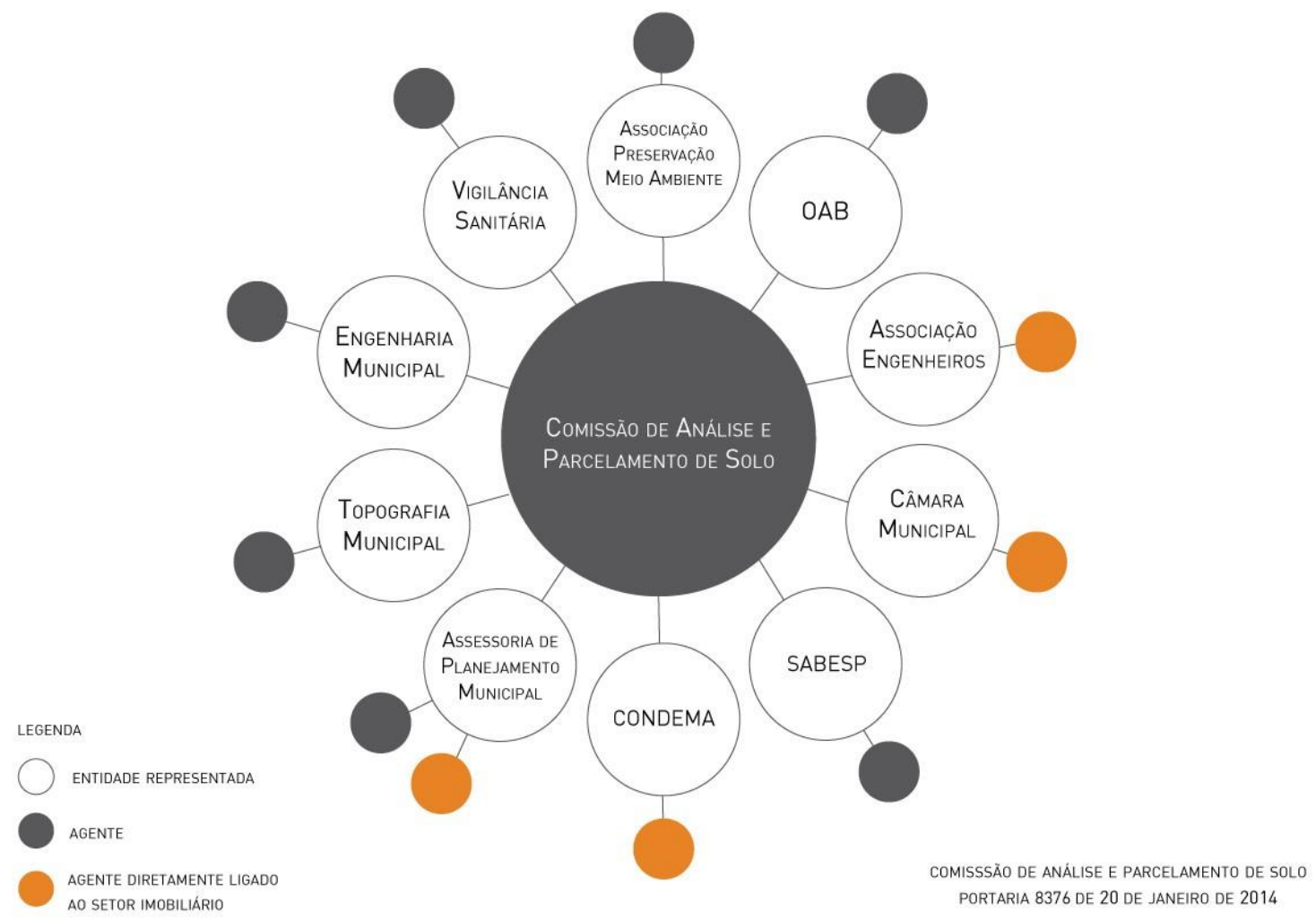

Figura 2 - Distribuição dos representantes na Comissão de Análise e Parcelamento do Solo (CAPS). Trabalho dos autores sobre dados da Prefeitura Municipal (São João da Boa Vista, 2014).

\section{Conclusões}

Pode-se afirmar que a Lei de Parcelamento de Solo 1.366/2001 alterou a dinâmica de mercado, causando uma concentração e beneficiando atores politicamente conectados. Ao mesmo tempo, a CAPS operou para que estes mesmos agentes privados obtivessem benefícios, por meio da deliberação de seus 
próprios projetos e de projetos de seus concorrentes. Por meio de reuniões, esta instância propunha aprovações, recomendações e até mesmo vetos a novos loteamentos e desmembramentos na cidade.

Este fato deu-se por meio de mudanças na legislação urbanística e também por distorções nas instâncias públicas de aprovação e controle de loteamentos, com a presença de funcionários de empresas loteadoras participando de deliberações que versavam sobre seus próprios projetos ou projetos de empresas concorrentes. Tal sistema era composto complementarmente de atores privados e estatais, cada qual proporcionando ao outro vantagens e privilégios.

Acredita-se que este é um exemplo significativo da baixa efetividade dos mecanismos de controle administrativo, operando assim muitas vezes em desfavor da coletividade, facilitando a obtenção de privilégios. Como alguns autores argumentam (Cappelletti, 2012; Chiodelli \& Moroni, 2015), determinados atores por meio de pressões e influências conseguem vantagens na aprovação de projetos, seja pela inobservância de irregularidades, seja por uma tramitação acelerada. Desta forma, conseguiriam alterar a dinâmica do mercado de maneira artificial, em detrimento da livre-concorrência.

Além disso, a tipologia de "loteamento fechado" foi criada, mesmo não havendo esta possibilidade prevista pela Lei Federal 6.766/79, que versa sobre parcelamento de solo urbano. A alocação de áreas institucionais foi alterada, de forma a maximizar o uso de solo urbano voltado exclusivamente para habitações. A possibilidade de transferir essas áreas para outras regiões da cidade, subvertendo assim sua função urbanística, possibilitou que frentes de expansão fossem criadas, tendo as empresas loteadores como beneficiárias.

A partir da análise desse caso, é possível compreender de que maneira práticas corruptivas se utilizam de instrumentos legislativos para obtenção de privilégios para atores politicamente conectados. A definição e uso desta legislação determinaram oportunidades econômicas segundo interesses privados. Possibilitou ainda, que uma instância de controle desse mercado fosse operada segundo esses interesses, enfraquecendo os mecanismos que deveriam limitar a discricionariedade administrativa, deformandoos. O resultado imediato desta dinâmica foi a maximização de possibilidades de negócio para determinadas empresas, diminuindo o risco capitalista, reduzindo a livre-concorrência e flexibilizando exigências e normas concernentes.

\section{Referências}

Ades, A., \& Di Tella, R. (1997). The new economics of corruption: a survey and some new results. Political Studies, 45(3), 496-515. http://dx.doi.org/10.1111/1467-9248.00093.

Alcaraz Ramos, M. (2007). De la corrupción urbanística a la corrupción de la democracia. In M. Alcaraz Ramos, El estado de derecho frente a la corrupción urbanística. Madri: La Lei.

Alfonsin, B. (2001). Políticas de regularização fundiária: justificação, impactos e sustentabilidade. In E. Fernandes (Ed.), Direito urbanístico e política urbana no Brasil (pp. 195-268). Belo Horizonte: Del Rey.

Banfield, E. C. (1961). Political influence. New York: Free Press.

Bardhan, P. (1997). Corruption and development: a review of issues. Journal of Economic Literature, 35(3), 1320-1346.

Bardhan, P. (2006). The economist's approach to the problem of corruption. World Development, 34(2), 341-348. http://dx.doi.org/10.1016/j.worlddev.2005.03.011.

Cappelletti, M. (2012). La corruzione nel governo del territorio (1. ed). Salerno: Booksprint.

Chiodelli, F., \& Moroni, S. (2015). Corruption in land-use issues: a crucial challenge for planning theory and practice. The Town Planning Review, 86(4), 437-455. http://dx.doi.org/10.3828/tpr.2015.27.

Chiodelli, F. (2018). The Illicit side of urban development: corruption and organized crime in the field of urban planning. Urban Studies. In press. http://dx.doi.org/10.1177/0042098018768498. 
Della Porta, D. \& Vannucci, A. (1994). Corruzione politica e amministrazione pubblica: risorse, meccanismi, attori. Bolonha: Il Mulino.

Gardiner, J. A., \& Lyman, T. R. (1978). Decisions for sale: corruption and reform in land use and building regulation. Michigan: The University of Michigan Press.

Gasparino, L. G. (2017a, 18 de fevereiro). MP e Polícia Civil realizam busca na Prefeitura e empresas (pp. 8). São João da Boa Vista: 0 Município.

Gasparino, L. G. (2017b, 18 de março). Promotor divulga primeiros documentos do 'Caso Hellen' (pp. 3). São João da Boa Vista: O Município.

Iglesias, F. (2007). Introdução. In F. Iglesias. Urbanismo y Democracia: alternativas para evitar la corrupción. Madri: Fundación Alternativas.

Kaufmann, D. (2005). Myths and realities of governance and corruption. Germany: University Library of Munich.

Klitgaard, R. (1988). Controlling corruption. Berkeley: University of California Press.

Lambsdorff, G. J. (2002). Making corrupt deals: contraction in the shadow of the law. Journal of Economic Behavior \& Organization, 48(3), 221-224. http://dx.doi.org/10.1016/S0167-2681(01)00217-7.

Leal, V. N. (1948). Coronelismo, enxada e voto. Rio de Janeiro: Forense.

Maricato, E. (2003). Metrópole, legislação e desigualdade. Estudos Avançados, 17(48), 151-166. http://dx.doi.org/10.1590/S0103-40142003000200013.

Nye, J. S. (1967). Corruption and political development. The American Political Science Review, 61(2), 417-427. http://dx.doi.org/10.2307/1953254.

Oliveira, L. F., Jr. (2017, 18 de março). MP quer que Hellen devolva 370 mil (pp. 3). São João da Boa Vista: 0 Município.

Pera, C. K. L. (2016). Processo contemporâneo de expansão urbana: legislação urbanística e lógicas de produção do espaço urbano: estudo da região metropolitana de Campinas (Dissertação de mestrado). Programa de Pósgraduação em Urbanismo, Pontifícia Universidade Católica de Campinas, Campinas.

Prestes, V. B. (2017) Corrupção urbanística: da ausência de diferenciação entre direito e política no Brasil (Tese de doutorado). Università del Salento, Lecce.

Rolnik, R. (1997). A Cidade e a Lei: legislação, política urbana e territórios na cidade de São Paulo. São Paulo: FAPESP/Studio Nobel.

Rose-Ackerman, S. (1978). Corruption: a study in political economy. New York: Academic Press.

São João da Boa Vista. (2001). Processo administrativo 5111/2001. São João da Boa Vista: Departamento de Engenharia e Fiscalização.

São João da Boa Vista. (2004a, 7 de maio). Projeto de Lei do Executivo no 80 de 2004. Altera a lei de parcelamento e uso do solo no município. São João da Boa Vista: Jornal Oficial do Município.

São João da Boa Vista. (2004b, 7 de julho). Lei Municipal nº 1.366/2004. Dispõe sobre o parcelamento urbano de São João da Boa Vista. São João da Boa Vista: Jornal Oficial do Município. Recuperado em 8 de fevereiro de 2018, de http://sapl.saojoaodaboavista.sp.leg.br/sapl_documentos/norma_juridica/5407_texto_integral

São João da Boa Vista. (2004c, 21 de setembro). Lei Municipal no 1.394/2004. Altera a redação do $\S 1^{\circ}$ o do artigo $8^{\circ} e$ artigo 39 das disposições transitórias, todas da lei no 1.366, de 07 de julho de 2.004 e dá outras providências. São João da Boa Vista: Jornal Oficial do Município. Recuperado em 8 de fevereiro de 2018, de http://sapl.saojoaodaboavista.sp.leg.br/sapl_documentos/norma_juridica/5520_texto_integral

São João da Boa Vista. (2004d). Processo Administrativo 7309/2004. São João da Boa Vista: Departamento de Engenharia e Fiscalização.

São João da Boa Vista. (2005). Processo administrativo 2518/2005. São João da Boa Vista: Departamento de Engenharia e Fiscalização. 
São João da Boa Vista. (2006a, 12 de setembro). Lei Municipal no 1.903/2006. Altera as redações dos $\$ \S 2^{\circ}$ e $3^{\circ}$ do Artigo $5^{\circ}$ e do $\S 1^{\circ}$ do Artigo $8^{\circ}$, todos da Lei $n^{\circ}$ 1.366, de 7 de julho de 2004. São João da Boa Vista: Jornal Oficial do Município. Recuperado em 8 de fevereiro de 2018, de http://sapl.saojoaodaboavista.sp.leg.br/sapl_documentos/norma_juridica/5337_texto_integral

São João da Boa Vista. (2006b, 27 de junho). Decreto Municipal no 2.046. Dispõe sobre a aprovação do Loteamento Fechado Morro Azul. São João da Boa Vista: Jornal Oficial do Município.

São João da Boa Vista. (2010, 15 de agosto). Decreto Municipal no 3.589. Dispõe sobre a permissão de uso do sistema viário, das áreas verdes e do sistema de lazer aos compromissários compradores do loteamento denominado MORRO AZUL II. São João da Boa Vista: Jornal Oficial do Município, no. 484.

São João da Boa Vista. (2014, 30 de janeiro). Portaria do Executivo no 8.376. Nomear Comissão de Análise e Parcelamento de Solo do Município de São João da Boa Vista. São João da Boa Vista: Jornal Oficial do Município, no. 567.

São João da Boa Vista. (2016). Plano estratégico 2050. Recuperado em 8 de fevereiro de 2018, de http://www.saojoao2050.com.br/userdata/public_uploads/Plano_SaoJoao2050/SJBV_USPCIDADES_PLANOSAOJO A02050_PARA\%20WEB.pdf

Savona, E. U., \& Mezzanotte, L. (1998). La corruzione in Europa. Roma: Carocci Editori.

Singer, P. (1982). Uso do solo urbano na economia capitalista. In E. Maricato (Ed.), A produção capitalista da casa (e da cidade) no Brasil industrial. São Paulo: Alfa-Omega.

Sparovek, G., Leonelli, G. C., \& Barreto, A. G. O. P. (2004). A linha imaginária. In P. Santoro, \& E. Pinheiro (Eds.), 0 planejamento do município e o território rural (Cadernos Pólis, No. 8). São Paulo: Instituto Pólis.

Transparency International. (2013). Global corruption barometer (p. 11). Berlin.

Villoria, M., \& Oset, M. (2007). La corrupción urbanística: conceptos básicos. In F. Iglesias (Ed.), Urbanismo y Democracia: alternativas para evitar la corrupción. Madri: Fundación Alternativas.

Viva São João. (2014). Relação de loteamentos (2004-2014). Recuperado em 8 de fevereiro de 2018, de http://www.vivasaojoao.org/2015/03/31/relacao-de-loteamentos-2004-2014/

Warren, M. E. (2004). What does corruption mean in a democracy? American Journal of Political Science, 48(2), 328343. http://dx.doi.org/10.1111/j.0092-5853.2004.00073.x.

\section{Editor: Fábio Duarte}

Recebido: Mar. 15, 2018

Aprovado: Ago. 12, 2018 